\title{
Effect of tool geometry variation on finish turning - A Review
}

\author{
M. Dograa,,a,V. S. Sharma ${ }^{\mathrm{b}}$, J. Dureja ${ }^{\mathrm{c}}$ \\ ${ }^{a}$ Department of Mechanical Engineering, SSG Panjab University Regional Centre, Punjab, India. \\ ${ }^{b}$ Department of Industrial Engineering, Dr.B.R.Ambedkar NIT Jalandhar, Punjab, India. \\ ${ }^{c}$ Department of Mechanical Engineering University College of Engg. Punjabi University Patiala, India.
}

Received 4 October 2009; Revised 19 October 2010; Accepted 20 December 2010

\begin{abstract}
The effect of cutting tool geometry has long been an issue in understanding mechanics of turning. Tool geometry has significant influence on chip formation, heat generation, tool wear, surface finish and surface integrity during turning. This article presents a survey on variation in tool geometry i.e. tool nose radius, rake angle, groove on the rake face, variable edge geometry, wiper geometry and curvilinear edge tools and their effect on tool wear, surface roughness and surface integrity of the machined surface. Further modeling and simulation approaches on tool geometry including one approach developed in a recent study, on variable micro-geometry tools, is discussed in brief.
\end{abstract}

Keywords: Curvilinear edge, rake angle, grooved tools, nose radius, variable geometry.

\section{Introduction}

Stringent control on the quality of machined surface and sub-surface during turning is most important consideration a part from considering the tool life. In order to attain sufficiently high production rates at minimum cost, optimization of cutting tool geometry is necessary [1],[2]. The design of cutting edge geometry and its influence on machining performance have been a research topic in metal cutting for a long time. Edge preparation has a critical effect on the tool life. A tool with poor edge preparation may chip and fail quickly [3]. Users expect to have more and more productivity in their machining processes (high removal rate of work-material) and low wear of their cutting tools (long tool life). These demands require major improvements in the design of cutting tools: new substrates, new coatings, cutting tool geometry and materials etc. According to tool manufacturers, the manufacturing procedures of their cutting tools, especially the micro-geometry preparation (cutting edge etc.), have a major influence on their performance and on their reliability [4]. Edge preparation must be carefully selected for a given application because it affects the surface integrity of the machined workpiece (white layer, residual stresses etc.) [5]. Heat generated during hard turning is also affected by edge preparation due to change in work material flow around the cutting edge. For example, a chamfered face provides excessive negative angle to the cutting action and results in high heat generation. PCBN tools rapidly wear out during hard turning at high cutting speeds mainly due to attained temperatures [6].

It is important to consider the tool-edge effect in order to

\footnotetext{
* E-mail address: mdogra7@gmail.com.

ISSN: 1791-2377 (c) 2011 Kavala Institute of Technology. All rights reserved.
}

better understand the chip formation mechanism and accurately predict machining performances, such as cutting forces, cutting temperatures, tool wear, surface finish and the machined surface integrity. The methods commonly employed include experimental, analytical, and numerical methods [7]. The tool geometry effects on turning performance parameters are mentioned in Figure1.

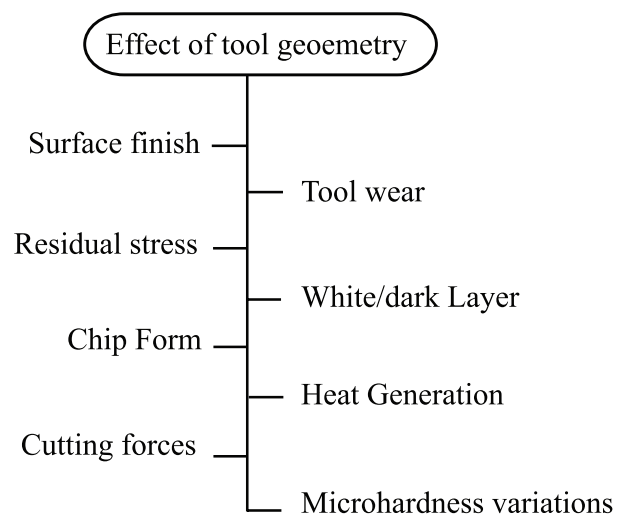

Figure 1. Effect of tool geometry on performance parameters in turning

It is demonstrated that the cutting tool edge geometry significantly influences many fundamental aspects such as cutting forces, chip formation, cutting temperature, tool wear, tool-life and characteristics like surface roughness and surface damage $[7,8]$.

Desired chip form in turning is C-type broken chips, helical broken chips with length ranges from 0.5 inch to 2 inch, while 
long helical unbroken chips with the length larger than 2 inch and snarled unbroken chips are undesired chip forms. Variation in cutting speed, feed and depth of cut can help in achieving the desired chip form in order to improve the productivity. But changing cutting conditions to break the chip is usually not feasible due to the requirements of the machining processes and their impact on tool life, surface finish and surface integrity. So the variation in the tool geometry is one of the important parameter to be considered for desirable chip form without hindering the turning performance [9]. From the literature it is clear that in order to enhance the turning productivity in terms of tool life, surface finish and surface integrity, variation in tool geometry is one of the major parameter to be considered. As mentioned in Figure 2 rake angle variations, groove on rake face, edge radius variations and curvilinear edge, approaching angle and side cutting edge variation in tools has been practiced by the researchers in order to study the turning performance in past. In this paper significant pool of studies on variation in tool geometry has been surveyed.

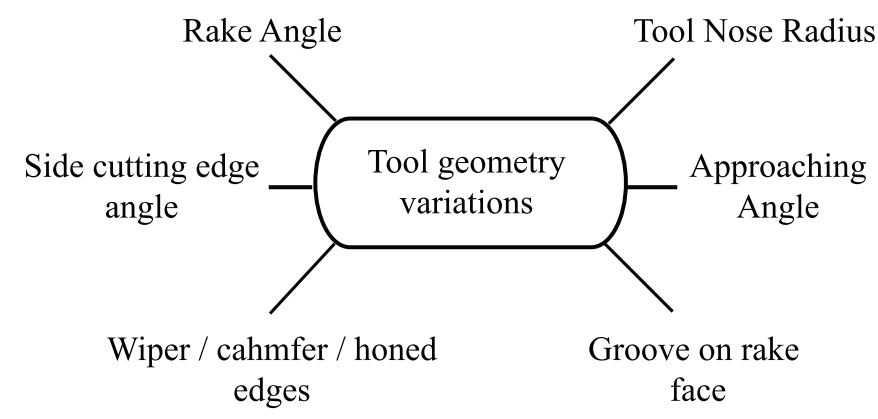

Figure 2. Tool geometry variation

The objective of this paper is to review the research progresses on tool geometry variations in turning i.e. edge geometry variations, groove on the rake face, edge radius variations and rake angle variations, further their affect on overall performance of the turning process. Further the use of advance FEA/ modeling techniques with tool geometry variations for prediction of process performance in turning is also discussed. Also a recent study reported on variable micro-geometry in PCBN tools is discussed in detail.

\section{Tool Edge (curvilinear edge/ wiper geometry):}

The design of cutting edge geometry and its influence on machining performance have been a topic of research in metal cutting for a long time. Emerging machining techniques such as hard turning and micromechanical machining, where the uncut chip thickness and the tool edge dimension are in the same order of magnitude, require cutting edges which can withstand high mechanical and thermal stresses, hence wear resistance, for a prolonged machining time. The chamfered/honed tool is recommended to prevent the chipping of the cutting edge and to impart strength to the cutting edge [10]. Wiper geometry tools perform better than the conventional tools for improved surface finish $[11,12]$. Tools with chamfered edge are used for machining hard materials due to their high edge strength. Chamfered cutting tool traps the work material over the cham- fered edge and the formed dead metal acts like a cutting edge, which increases the tool edge strength and reduces the tool wear [13]. Author reported that residual stresses generated by large edge hone tools are typically more compressive than stresses produced by small edge hone tools and they also leave white-layers. In addition, the effects of edge geometry play an important role in thermoplastic deformation of the workpiece [14].

In PCBN cutting tools, several types of edge preparation can be made for hard turning operations, including sharp edge (with no additional edge processing to strengthen edge), chamfers, hones, and chamfers plus edge hones. However, in most cases, chamfer with edge hones is preferred edge preparation in hard turning [15]. The cutting tool edge geometry, which means the chamfer angle, chamfer width and edge hone has a significant influence on tool life and to a large extent determines the surface finish and surface integrity of the machined part. Tool wear, on both flank and rake face constitutes a change in edge geometry. The feeds and depths of cut used in finish hard turning are relatively small $(0.2 \mathrm{~mm})$, and generally of the same magnitude as that of tool edge geometry. As a result, cutting is confined to a small area on the nose radius and edge. Due to the extreme hardness of the workpiece in hard turning, a negative rake angle with strong edge geometry with a chamfer and hone is employed, in order to withstand the high cutting forces, stress and temperature that are generated during turning $[16,6]$.

Author investigated the effect of turning parameters on residual stress in finish turning with focus on the depth of residual stress. The material used was case carburized steel with hardness in the range of 58-62 HRc. They reported that the residual stresses after hard turning and superfinishing are more compressive and reach deeper to the machined surface than that after grinding and superfinishing. In order to increase the plastic deformation zone, several tool geometries were investigated. They confirmed that the hone edge and the double chamfer geometries offered the greater subsurface penetration, and produced larger values of maximum compressive stress. In their experiment, a maximum compressive circumferential stress of $800 \mathrm{MPa}$ was obtained at a depth of $20 \mu \mathrm{m}$ from the machined surface by using the double chamfer geometry, $780 \mathrm{MPa}$ by using the $20 \mu \mathrm{m}$ hone edge preparation, and only $250 \mathrm{MPa}$ by using a sharp edge [17].

In hard turning, as the material is harder, specific cutting forces are larger than in conventional turning. Because of this the small cutting depth required and cutting takes place on the nose radius of cutting tools thus the tools are prepared with chamfered or honed edges to provide a stronger edge geometry that is less prone to premature fracture [18]. Cutting with chamfered or honed edge equates to a large negative effective rake angle, while neutral or positive rake angles are typical in conventional machining. The large negative rake angle yields increased cutting forces compared to machining with positive rake tools and also induces larger compressive loads on the machined surface. During the finish turning of AISI 52100 bearing steel hardness of 60HRC with PCBN (Polycrystalline cubic boron nitride) inserts having chamfered geometry $(0$, $10,20,30 \mathrm{deg})$, honed edge radius $(.01 \mathrm{~mm})$, chamfered width 
$.1 \mathrm{~mm}$, a very small feed rate and depth of cut are used. The cutting area is confined to a small area in the front tip of the cutting edge, or in the area of chamfer zone. As shown in Figure 3 cutting forces increase with the increase of the chamfer angle. The passive forces (Fp) in the passive direction are higher than the primary cutting forces $(\mathrm{Fc})$ in cutting direction and increase more rapidly with the increase in chamfer angle [19].

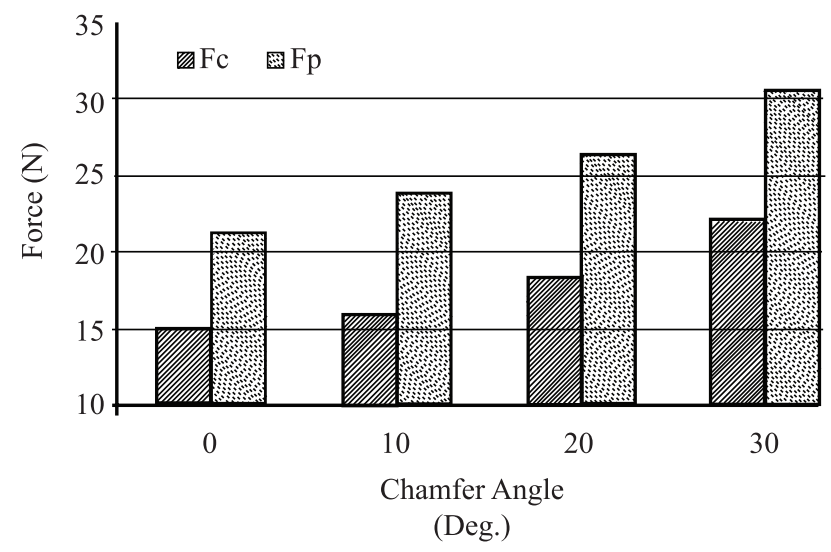

Figure 3. Correlation of cutting force and chamfer angle

In finish hard turning there is an optimum value of chamfer angle where the tool life is maximum. Results indicated that tool life reaches to its maximum up to $15^{\circ}$-chamfer angle and after that it reduces drastically. The tool life was measured up to the value of $0.2 \mathrm{~mm}$ flank wear, in order to avoid excessive white layer induced on the workpiece surface due to the higher temperature under the large flank wear. As per FE analysis the cutting edge with $15^{\circ}$ chamfer angle has the smallest value of flank wear as compared to other cutting tools [20].

The benefits of honed/-chamfered edge tools seem more obvious when turning commercially available Inconel-718 with PCBN tools. The different cutting edge geometries are used during turning. Cutting edge preparations employed include large chamfer $\left(100 \mu \mathrm{m} \times 30^{\circ}\right) \mathrm{CWI}$, small chamfer $\left(100 \mu \mathrm{m} \times 20^{\circ}\right)$ CWII and large chamfer plus honed edge $\left(100 \mu \mathrm{m} \times 30^{\circ}\right) \mathrm{CH}$, in order to eliminate the edge-related problems during machining such as edge chipping, cracks and breakage. It is observed that the cutting force component is significantly higher (two to three times) in magnitude than the other force components. The cutting forces reduce considerably at $475 \mathrm{~m} / \mathrm{min}$ cutting speed, whereas the magnitude of forces is higher at $125 \mathrm{~m} / \mathrm{min}$ cutting speed. This can be attributed to the increased thermal softening of the work material at higher cutting speed [21]. In hard turning with chamfered/honed tools the overall magnitude of radial force is not affected because it acts more or less parallel to the chamfered cross-section on the cutting edge. As the tool wear progresses it affects the rake angle negatively and thus increases cutting force, even by increasing the cutting speed the force component does not reduce. Increasing tool tip radius causes main cutting force to increase [22].

The geometry of the cutting edge and its preparation can play a significant role on the insert performance, directly affecting tool life, surface finish and surface integrity. Turning tests were performed on nickel-based alloy, INCONEL718TM, with $\mathrm{Al}_{2} \mathrm{O}_{3}$-based, $\mathrm{Al}_{2} \mathrm{O}_{3}$-based $+\mathrm{SiC}$ and $\mathrm{PCBN}$ inserts having modified edges. The round edge inserts were best in terms of tool wear and surface roughness. The round ceramic inserts produced compressive layer on the machined surface, which is beneficial for fatigue resistance. Notching was common phenomenon observed on all the inserts. It was possible to produce surface roughness Ra below $.5 \mu \mathrm{m}$ when turning INCONELTM-718 at $500 \mathrm{~m} / \mathrm{min}$. Such result strongly encourages the use of the modified edges for work materials where better fatigue resistance is required [23]. The influence of hone radius and chamfer angle is such that when value of both the variables increase, burnishing at the cutting edge becomes a dominant factor in the chip formation. The burnishing process is prone to produce material side flow leading to the deterioration of the final surface quality. It was also observed that hone radius put more influences on the cutting edge temperature than chamfer. When hone radius increases from 20 to $100 \mu \mathrm{m}$ (at chamfer angle of $20^{\circ}$ ), the maximum edge temperature increases to more than $90^{\circ} \mathrm{C}$. Therefore, using chamfer plus hone for cutting edge preparation is better from the tool wear point of view, if required residual stress level can be reached [24]. Chamfer tool helps to increase compressive residual stress but its effect is less than that of increasing the hone radius. It is recommended that chamfer plus hone radius be used to obtain best residual stress profile. The best approach is to use large hone radius cutting tools [25]. While machining with the chamfered tools, the Ra $.2 \mu \mathrm{m}$ is attained only for feed rates smaller than $0.06 \mathrm{~mm} / \mathrm{rev}$. Increase in productivity together with good finish can be achieved with these tools, if only the last pass of the cutting is made at these conditions. The cutting forces developed in hard metal turning with CVD diamond tools increase with the bluntness of the cutting edge in the following order: sharp $<$ chamfer $<$ hone [26]. During the orthogonal turning of AISI 4340 steel, waterfall-hone (ovallike edge) tools yielded lower forces than honed and chamfered tools. Waterfall hone with 20:40 mm edge dimension yielded the lowest thrust forces. It was clear from the experimental results that, as edge radius increases, thrust forces increase. Large edge radius is not suitable for machining low uncut chip thickness. The purpose of using cutting tools with curvilinear edges is to protect the cutting edge from chipping, to improve its impact resistance, and to increase surface area of heat transfer on the cutting zone [10]. Chamfered tools are usually used in rough and interrupted turning. The stable trapped material (dead metal zone-DMZ or cap) in front of the chamfered cutting edge increases the strength of the tool tip; however, it also increases cutting forces [27]. Honed tools are employed in finish turning operations since the application of hone to the tool tip increases the impact resistance. Waterfall hone edge geometry combines the appropriate characteristics of chamfered and honed tools such as increased tool tip strength and increased rake angle. Its oval-like geometry eases the flow of work material in front of the tool [28].

During the finish hard turning of AISI H13 steel the effects of cutting edge preparation, workpiece surface hardness and cutting conditions on the surface roughness and cutting forces is explored, result reveals that the effect of cutting edge geometry on the surface roughness is remarkably significant. Especially, honed edge geometry and lower workpiece surface 
hardness resulted in better surface roughness. Cutting edge geometry, workpiece hardness and cutting speed are found to be affecting force components. The lower workpiece surface hardness and small edge radius resulted in lower tangential and radial forces [29]. Hard turning of martensitic stainless steel was performed using wiper coated carbide tool at various cutting speeds and feeds. The set parameters combination of low cutting speed and low feed produced the longest tool life. Wiper coated carbide tool achieved very fine surface finish, much better than the theoretical values and within the strict range of finish machining criteria [30].

\section{Variable Micro geometry tools experimental and mod- eling aspects:}

A uniform edge micro-geometry along the corner radius of the insert creates a very low edge radius to uncut chip thickness at the minor cutting edge. This causes more ploughing than shearing at the minor cutting edge resulting in excessive heat built-up and rapid wear. A variable edge micro-geometry along the corner radius of the insert has the potential to reduce this heat built-up at the cutting edge enabling hard turning at higher cutting speeds and feeds with less tool wear [31, 32]. While uniform edge preparation strengthens tool cutting edge, it makes cutting less efficient especially when the ratio of uncut chip thickness to tool radius decreases. This is especially true when friction factor increases with decreasing uncut chip thickness to edge radius ratio. The work material is trapped near end of the uncut chip geometry along the corner radius. Inefficient cutting results in increased strains in the workpiece, which in turn increases mechanical and thermal loads and results in high temperatures [33]. In variable edge design, the key parameter is the ratio of uncut chip thickness to edge radius. If this ratio is known, for a particular cutting condition a variable cutting edge can be designed. Variable edge preparation is not limited to honed micro-geometry inserts. Chamfered and waterfall type micro-geometry inserts can also have variable edge preparation. The purpose of continuously changing the chamfer angle along the corner radius is to alter the locations of high temperature zones and reduce the possibility of a crater wear formation.

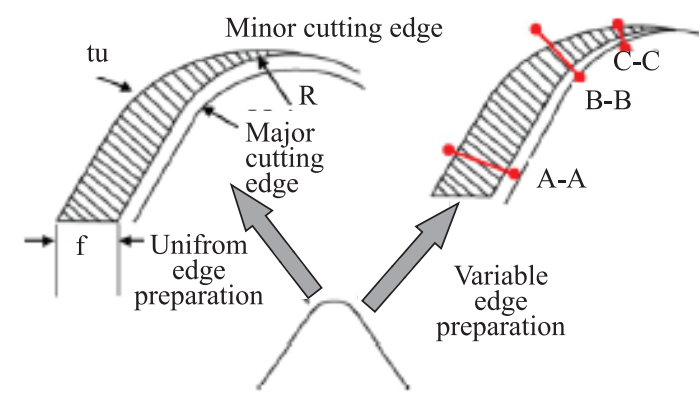

Figure 4. Uniform Vs variable micro-geometry design

As mentioned in Figure 4 for variable micro-geometry tool edge radius at point $\mathrm{A}-\mathrm{A}$ is greater than that of at point $\mathrm{B}-\mathrm{B}$ and $\mathrm{C}-\mathrm{C}\left(\mathrm{r}_{\mathrm{A}}>\mathrm{r}_{\mathrm{B}}>\mathrm{r}_{\mathrm{C}}\right)$. Author studied the turning of annealed and hardened AISI 4340 steel (40 HRc) using PCBN inserts
$(50 \% \mathrm{CBN}+40 \% \mathrm{TiC}+6 \% \mathrm{WC})$ with four different microgeometries (uniform chamfer with $0.1 \mathrm{~mm}$ chamfer height and $20^{\circ}$ angle, uniform hone with $50 \mu \mathrm{m}$ (and $40 \mu \mathrm{m}$ ) edge radius, waterfall (WF) hone with $\mathrm{re}=30: 60 \mathrm{~mm}$ radii, variable hone edge with $r_{A}=50 \mu \mathrm{m}, r_{B}=10 \mu \mathrm{m}$ radii). Results indicate that more efficient cutting has been performed due to variable edge micro-geometry design that resulted in lower radial forces but slightly higher tangential forces. Further variable micro-geometry tool design reduces the heat generation along the tool cutting edge. Variable micro-geometry insert cutting edge induces less plastic strain on the machined workpiece. Tool wear is decreased with the use of a variable micro-geometry insert. If the variable edge is properly designed for the given cutting conditions it can lead to improvement in overall productivity during hard turning. 3D finite element modeling is utilized to predict chip formation, forces, temperatures and tool wear on uniform and variable edge micro-geometry tools. In this study, finite element modeling software (Deform 3D) is used to study the effects of uniform and variable micro-geometry edge design on process variables. This FEM software is based on an implicit Lagrangian computational routine with continuous adaptive remeshing. The workpiece is modeled as rigid-perfectly plastic material where the material constitutive model of this deformable body is represented with Johnson-Cook material model as represented by Eq. (1), where $\mathrm{A}=1504 \mathrm{MPa}, \mathrm{B}=569 \mathrm{MPa}, \mathrm{n}=$ $0.22, \mathrm{C}=0.003, \mathrm{~m}=0.9$, Tmelt $=1426^{\circ} \mathrm{C}$ are the parameters for AISI 4340 steel.

$$
\bar{\sigma}=\left[\mathrm{A}+\mathrm{B}(\bar{\varepsilon})^{n}\right]\left[1+c \ln \left(\frac{\bar{\varepsilon}}{\bar{\varepsilon}_{o}}\right)\right]\left[1-\left(\frac{T-T_{0}}{T_{\text {melt }}-T_{0}}\right)\right]
$$

Workpiece model includes 200,000 elements. The bottom surface of the workpiece is fixed in all directions. The cutting tool is modeled as a rigid body, which moves at the specified cutting speed by using 125,000 elements. All simulations were run at the same cutting condition $(\mathrm{V}=300 \mathrm{~m} /$ $\min , \mathrm{f}=0.15 \mathrm{~mm} / \mathrm{rev}, \mathrm{d}=1 \mathrm{~mm})$. In 3D FE modeling, constant shear friction factor $(\mathrm{m})$ and pressure-dependent shear friction factor $m=f(p)$, have been benchmarked to identify the friction between micro-geometry tool and workpiece. Predicted temperature distributions that smallest hot zone formed on the variable honed tool and maximum temperatures of 853,724 , 664 and $626^{\circ} \mathrm{C}$ are predicted for uniform chamfered, uniform waterfall (WF 30:60), uniform honed (Hone 40) and variable honed (Var. Hone 50) inserts, respectively. In addition, the heat is seen more uniformly distributed along the cutting edge of the variable micro-geometry insert. Finite element simulations are also utilized to predict tool wear and result reveals that variable micro-geometry edge design has the lowest wear rate under the same cutting conditions [34].

\section{Tool nose radius variations:}

Among various machining parameters, tool nose radius has a significant contribution to the cutting dynamics and the stability of a machining process. Nose radius is a major factor that 
affects surface finish of the machined surface. A larger nose radius produces a smoother surface at lower feed rates and a higher cutting speed. Large nose radius tools have, along the whole cutting period, slightly better surface finish than small nose radius tools $[35,36]$. The edge of a real tool always has a finite sharpness. Commercially available cutting tools usually have a tool edge radius varying from 5 to $250 \mu \mathrm{m}$. In general, a coated tool has a larger tool edge radius than does an uncoated tool. Much experimental evidence shows that tool edge geometry plays a critical role in precision machining, where the feed rate is small and on the same order of magnitude as tool edge dimension [2, 32]. Nose radius is a major factor that affects surface roughness. A larger nose radius produces a smoother surface at lower feed rates and a higher cutting speed. However, a larger nose radius reduces damping at higher cutting speeds, thereby contributing to a rougher surface. Further during cutting with a tool that has a large nose radius, a large part of the chip will have a chip thickness less than the minimum chip thickness value. In addition, increasing the nose radius has a direct effect on cutting forces, leading to a significant increase in the ploughing effect in the cutting zone. Increasing the ploughing effect leads to more material side flow on the machined surface. In general, increasing the nose radius increases the level of tool flank wear. Cutting with a large nose radius results in a higher value of cutting forces due to the thrust force component. On the other hand, cutting with a small nose radius prolongs tool life, which can be explained by the reduction in the ploughing force [37]. The significance of the effect of the edge radius increases at smaller uncut chip thickness. Thus during turning of three different materials (gray cast iron, 2024 aluminum and commercially pure zinc) feeds were selected such that the ratio of uncut chip thickness to edge radius $\left(h / r_{n}\right)$ varied between 0.5 and 5 . This represents the range commonly seen in the operations of practical interest i.e. hard turning and finishing operations. It is found that the machining force components are sensitive to changes in edge radius on the order of the measured edge variation [38].

During turning result indicates that the tool-chip frictional shear stress around the edge is a very important parameter, which influences the optimum edge radius for each application. Further the chip thickness and tool-chip contact length decreases with the increase of the cutting edge radius. The average shear strain in the primary shear zone and the corresponding strain rate are very significantly affected with nose radius increase [39]. Author investigated the effects of tool nose radius and tool wear on residual stress distribution in hard turning of bearing steel JIS SUJ2. Three types of CBN tools with different nose radius $(0.4,0.8$ and $1.2 \mathrm{~mm})$ are used and result revels that the increase of the tool nose radius leads to an increase of the thrust force greatly. The ratio of the thrust force to cutting force and the ratio of the thrust force to feed force increase with the increase of the tool nose radius. There exists a tendency that the residual stresses induced at the machined surface shift from compressive stress to tensile stress as the nose radius increases in the cutting condition of this study. The effect of the nose radius on the residual stress distribution decreases greatly with the increase of the tool wear [40]. Tool nose radius effects on finish turning of hardened AISI 52100 steel was investigated. Results reveals that large tool nose radii only give finer surface finish, but comparable tool wear with small nose radius tools. Specific cutting energy slightly increases with tool nose radius. Tool life based on flank wear increases with increase in nose radius. However, reaches a constant at nose radius greater than $0.4 \mathrm{~mm}$. On the other hand, tool life based on surface finish shows a local maximum at 0.8 $\mathrm{mm}$ nose radius. It was suggested that large nose radii result in severe groove wear, and therefore, poor surface finish. Other than surface finish aspects, tool nose radius also affects uncut chip geometry, and thus, ratio of uncut chip thickness to edge radius that may affect plowing forces in the hard turning process. More interestingly, the distance from the cutting edge to the nominal machined surface changes across the cutting edge and is a strong function of tool nose radius as shown in Figure $5[41]$.

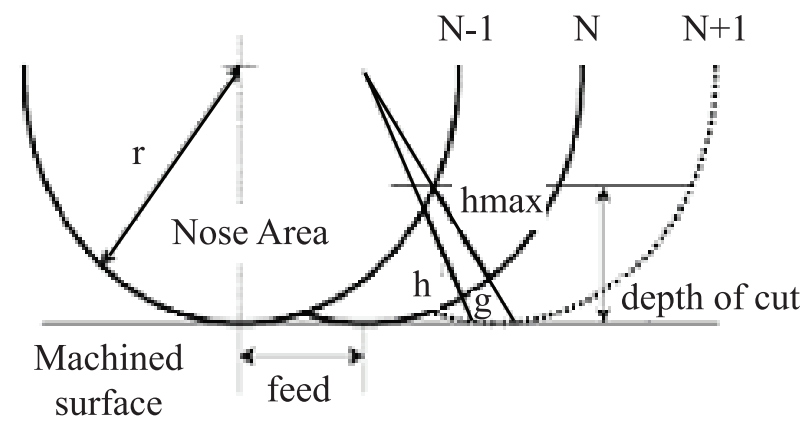

Figure 5. Tool nose area showing uncut chip thickness $(h)$ and the distance $(g)$ from the cutting edge to the final machined surface

Author revealed that increasing edge radius to a point that the edge roundness is larger than the uncut chip thickness actually decreases the effective rake angle towards the negative value. Hence a large edge radius has a similar effect to a negative rake angle i.e. to generate compressive residual stress beneath the machined surface [42].

The effect of tool edge geometry on work material subsurface deformation and through-thickness residual stresses for machining of AISI 52100 steel with PCBN tools is evaluated. Results indicated that the thickness of residual stress in large edge honed tools is deeper than in small edge honed tool. Further large edge honed tools produce more compressive residual stresses than small edge honed or chamfered tools. This can be explained by the stress state produced by the tool as it slides across the work material during turning. As shown in

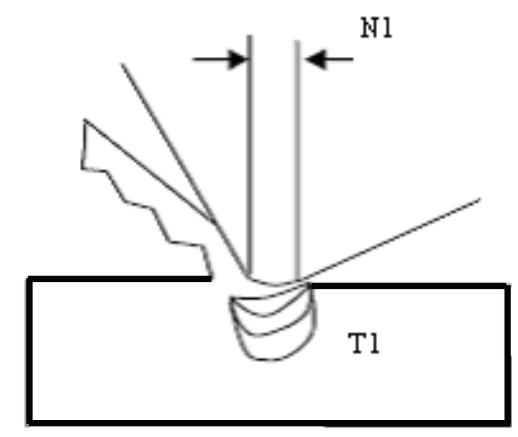

Figure 6 (a). Effect of small edge honed on induced stresses 


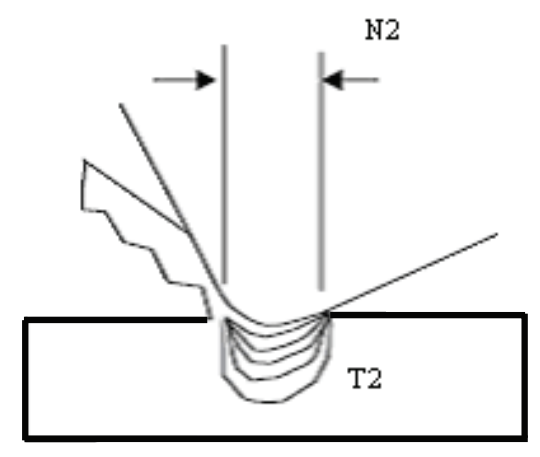

Figure 6 (b). Effect of large edge honed on induced stresses

Figure 6 (a) \& 6(b) the large edge honed tools (N2) result in increased frictional interaction between the tool and the workpiece. The interaction caused by large edge honed tools is larger than the interaction caused by small edge honed tools (N1). A large edge honed tool causes an increase in the tensile stress area behind the tool (T2) relative to the small edge honed (T1) due to the increased interaction length. Thus the increase in the tensile field behind the tool produces larger compressive residual stress [43].

During hard turning with $\mathrm{CBN}$ tools having different nose radius, results indicate that the compressive residual stress induced at the machined surface in the depth of cut of $0.1 \mathrm{~mm}$ is larger than that in the depth of cut $0.2 \mathrm{~mm}$. With the nose radius of $0.8 \mathrm{~mm}$, the residual stress at the machined surface was a residual compressive stress, but the magnitude of these residual compressive stresses is small in comparison to the nose radius of $0.4 \mathrm{~mm}$. Further it can be inferred that the stress pattern on the machined surface shifts from compressive stress to tensile stress as the nose radius increases in the cutting condition of this study [44].

\section{Grooved tools (Restricted Contact Tools):}

Chip control plays a vital role in machining. With the use of grooved/restricted contact tools effective chip control can be achieved i.e. desirable chip breakability, possible power reduction, operators safety and good surface finish [45]. The disposal of long continuous chips produced at high cutting speeds has posed a problem for industry in the age of automation. For easy disposal of chips, the volume of chips relative to the volume of the same material in bulk should be as low as possible. It is reported that well broken chips have volume ratio of between 3 and 10, where as entirely unbroken chips have volume ratio of 50. Long chips curl around the tool and can pose serious hazards to the workpiece surface, the operator and the machine-tool operations. The situation becomes more critical under the environment of automated machine loading, unloading and in process inspection of the machined parts [46, 47]. To overcome this difficulty, a number of researchers have investigated effective control of chip flow and chip breaking. Using an obstacle across the chip flow direction, commonly known as chip breaker or chip former, one can control chip curl. Broadly speaking there are two types of chip breakers: (1) obstruction type (2) Groove type. Obstruction type is fur- ther divided into two categories (a) step type chip breaker (b) ram type chip breaker [48]. The effect of increasing feed was an increase in length of contact between chip and tool, which resulted in extension of heated area further from the edge to the rake face accompanied by an increase in the maximum temperature. The artificial reduction of chip tool contact length substantially reduces the power consumed by the cut and as a result, heat generated is reduced [49]. Restricted contact tools (RCT) are also called artificially controlled contact tools. Their land length is less than the natural tool-chip contact length for a given set of cutting conditions [50]. As per Figure 7 the area of contact between chip and tool is less with restricted contact tools (RCT) as compared to conventional tools thus restricted contact tools offer several advantages for machining processes, such as substantial reduction in power consumption, lower tool-chip interface temperatures and improved surface integrity of the machined parts [49].
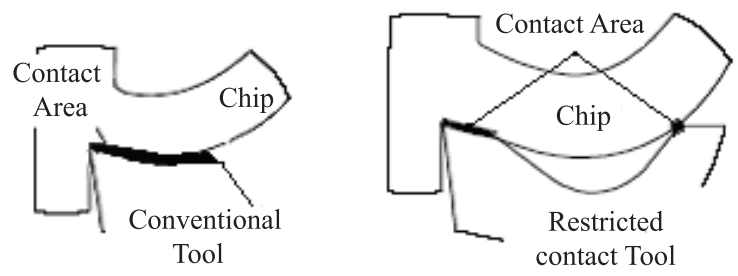

Figure 7. Tool tip contact area of Conventional and RCT tool while turning

On the basis of turning tests under a wide range of cutting conditions with commercially available grooved tools, the results achieved are quite satisfactory. Many groove-type chip breaker tools, which have a primary rake land between the cutting edge and chip-groove, have been widely applied in modern automatic machining operations [51]. These tools are also referred to as restricted contact grooved tools. The restricted contact effect in machining with grooved tools forms a basis for the generated chip to back-flow into the chip-groove and hence it provides favorable conditions for the chip to be broken. In this study restricted contact grooved tools produced from sintered carbides P20 are used to cut medium carbon steel under dry conditions. The results of experimentation are validated through developed model. The chip back-flow angle is defined first. Considering the contact between the chip and the chip groove backwall, the predicted chip back-flow angles are compared with their experimental results for a given set of machining conditions. The importance of chip back-flow angle is that it directly governs the tool-chip contact pattern. Experimentally chip back-flow angle is measured by using high speed filming technique. If the chip back-flow angle is less than the tool secondary rake angle, the generated chip will be in contact with the primary rake face only; otherwise, the chip will be in contact with both the primary and secondary rake faces, which adds to the complexity in the machining processes. Study shows that the state of stresses in the plastic deformation region is one of the most important factors governing chip back-flow. Chip-form/chip-breakability and tool-wear/tool-life are two of the major machining performance measures that have been the subject of extensive study over several decades. Understand- 
ing the chip-flow and curl mechanisms is very essential for predictive assessment of the chip breaking process. In practical machining operations such as turning, grooved tools are used rather than flat-faced tools to effectively curl and break the chips into small sizes and shapes for handling and disposal purposes. It has been shown that the nature of chip-curl and breaking contributes to the decrease in tool-life and reduction in cutting forces [52]. The beneficial effect of controlled contact cutting with respect to energy reduction became more pronounced with an increase in feed rate and depth of cut. During the turning of $\mathrm{C} 45$ carbon steel, chromium alloy steel and austenitic steel with coated indexable inserts of TNMG having four different chip groove geometries, results reveal that specific cutting energy seems to be governed remarkably by the contact length. Chip breaking increases steadily at higher feed rates and saving in cutting power consumption can be achieved by controlling the contact length at higher feed and depth of cut [53].

To obtain an optimum tool performance for providing good chip-breakability and tool life, it appears that the contact length should be in the range of $55-65 \%$ of the natural contact length. The associated benefits resulting from the effects of restricted tool contact are a tendency towards minimum power consumption, lower cutting forces and reduced cutting temperature [54]. During the machining of AISI 1045 steel with coated (TiN/TiCN/TiC) grooved tools actual temperature distribution at various points in the groove was studied. It was observed that after $50 \mathrm{~s}$ of machining, the maximum temperature was located at the secondary face of the tool and after an additional $190 \mathrm{~s}$ the backwall area temperature increased by approximately $13 \%$ and the location of the maximum temperature would be an area of high tool wear rate. Thus temperature distribution clearly indicates the advantage of using grooved tools [55].

Inappropriate design of the chip-grooves or obstructions can cause "unfavorable" flow of the chip resulting in wear of the obstruction and consequent tool failure. At low feed conditions, i.e. for cases where the tool face land is large with respect to the feed, chip-groove utilization is very low and the chip strikes the backwall directly and leads to abrasive wear, when the feed is very high compared to the tool face land. Smallness of the land not only makes the tool edge vulnerable to chipping, but also, the high feed conditions force the chip to have a much larger back-flow. The chip in this case is forced to remain in contact with larger section of the rake and groove-face (inner wall) and therefore, curls naturally before coming in contact with the backwall. The uneven wear pattern results in failure of the tool edge without significant wear of the backwall. In such cases, extremely high contact pressures at the tool nose results in accelerated nose wear. As shown in Figure 8 there is an optimum utilization of the chip-groove, in which major part of the chip-groove is utilized. The uniform pressure on the tool edge and the backwall normally results in a combination wear of the nose, rake face and the backwall. Combination wear generally results in a more predictable tool-wear and longer tool-life. For conditions involving a lesser side-curl, the chip deformation on the inside surface is less. This result in lower formation of burrs and consequently, lesser depth of notch wear [52].

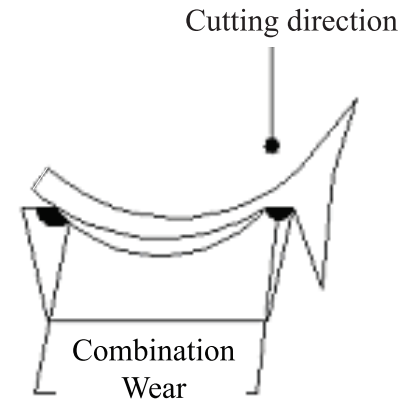

Figure 8. Combination wear in grooved tools

The target of a tool designer in using restricted contact length is to produce acceptable chip form and to reduce cutting forces. The common factor affecting both tool life and chip form is the contact length. In general tool-chip contact length decreases if the cutting speed is increased. Tool-chip contact length increases if the feed increases. Tool-chip contact length increases with increasing depth of cut. During turning of carbon steel with carbide tools with various RCL (restricted contact length), reduction of the contact from the natural length leads to reduction in flank wear. If the contact length is too heavily restricted, tool wear will increase rapidly. Extreme reduction in contact length also leads to a concentration of a high specific compressive stress on this small area. The optimum contact length would appear to be in the range of 55-65\% of the natural contact length. For a low combination of cutting speed and feed, the tools with restricted contact length show a low too 1 temperature. For high combination of cutting data, tools give better performance for less time and after that performance deteriorates [56]. Author reported that the tool with chip breaker geometry has smallest friction angle. Further it is indicated that for RCL tools, the min. and max. speed ranges are decided on the basis of stability in the specific cutting energy [57].

Some time grooves on the rake face helps in proper distribution of the cooling fluid at the chip tool contact. Author reported that during machining of steel rods (AISI 1040 and E4340C steel) with carbide inserts having grooves along the cutting edges and hills on the tool rake face as mentioned in Figure 9, cryogenic cooling reduces the average cutting temperature, because the above said geometry has helped the cryogenic jet to come closer to the chip tool interface thus effectively cooling the interface [58].

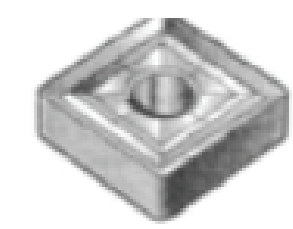

Figure 9. Carbide insert having grooves along the cutting edge

\section{Rake angle variation:}

For single point cutting tool most important angle is back rake angle. The back rake angle affects the ability of the tool to shear the work material and form the chip. It can be positive or 
negative. Positive rake angles reduce the cutting forces resulting in smaller deflections of the workpiece, tool holder, and machine. If the back rake angle is too large, the strength of the tool is reduced as well as its capacity to conduct heat. In machining hard work materials, the back rake angle must be small, even negative for carbide, PCBN and diamond tools. The higher the hardness, the smaller the back rake angle shall be used [59]. The magnitude of rake angle has significant effects on the performance of the cutting tool and the surface integrity generated during machining [60]. Author conducted hard turning experiments on hardened M50 steel HRC 61. Tests were conducted using different tools while also varying the depth of cut. They found that M50 consistently showed compressive residual stress at the surface. The amount of residual stress varied from -600 to $-1300 \mathrm{MPa}$. The effective rake angle and nose radius of the tool affect the amount of residual stress generated. Higher negative rake angle and smaller nose radius create a more compressive residual stress profile. The experimental data showed that depth of cut does not affect the amount of residual stress generated in hard turning [61].

Residual stresses were measured by means of the X-ray diffraction method. During turning with CBN tools result reveals that the residual stresses were tensile at the surface for different rake angles. However, at a depth of about 5-10 $\mu \mathrm{m}$, only compressive stresses could be observed. When the effective rake angle was decreased to $-21^{\circ}$ the level of compressive stresses increased along with the effective depth of cut. With further decrease of effective rake angle to $-41^{\circ}$ the depth to which residual stress level was affected was much higher. A greater negative rake angle gives higher compressive stresses as well as a deeper affected zone below the surface. The level of compressive stress below the surface increases constantly with higher feed rates. Further variation in cutting depths did not affect residual stress. Thus by controlling the feed and rake angle, it is possible to generate tailor-made stresses in the product [62]. Author investigated the variation of tool rake angle on main cutting force during turning of different materials, results reveals that for AISI 1020 the main cutting force shows decreasing trend as the rake angle increases from $0^{\circ}$ to $20^{\circ}$. But for UNS C23000 specimen the main cutting force remains unchanged with variation in rake angle from $0^{\circ}$ to $20^{\circ}$. Further it is found that when the main cutting force and chip formation are considered together, the optimum value of rake angle for AISI 1020 material is $\gamma=12^{\circ}$ and for UNS C23000 $\gamma=0^{\circ}$ [63]. Author established that negative rake angle tends to generate compressive residual stress whereas positive rake angle tends to induce tensile residual stress. Further it is suggested that creating a chamfer on the cutting edge has a similar effect as creating a negative rake angle, by which the maximum compressive residual stress in the subsurface can be increased [64].

\section{Modeling techniques with tool geometry:}

Machinability database systems are essential for selecting optimum process parameters during the process planning stage, which represents an important component in Computer Integrated Manufacturing (CIM). Researchers over the years have been trying to develop a metal cutting model analytically and numerically. For the last one decade, finite element modeling in particular has become increasingly popular due to the advancement in computers and the development of complex codes. The material flow stress properties are one of the most important factors in dealing with analytical and finite element method (FEM) solution accuracy [65].

Author reported the comparative analysis of empirical and experimental results of main cutting force with varying rake angle. There are many factors influencing the main cutting force as mentioned in equation (3). The most important factors are rake angle factor $(\mathrm{k} \gamma)$, cutting speed factor $(\mathrm{kv})$, tool wear factor (ka), and tool material factor (kt). The developed empirical equation is given below. Where Ks is specific cutting stress.

\section{$\mathrm{Fc}=\mathrm{A} \cdot \mathrm{Ks} \cdot \mathrm{Kv} \cdot \mathrm{K} \gamma \cdot \mathrm{Ka} \cdot \mathrm{Kt}$}

Result revels that empirical and experimental results show a similar trends. The deviation values exhibited that empirical results are in agreement with experimental results by more than $90 \%$. Main cutting force increases with increased negative rake angle values and decreases with increased positive rake angle values. Main cutting force for all cutting speeds is high for negative rake angles [66].

Based on large-strain deformation theory and by means of the updated Lagrangian formulation and the Prandtl-Reuss flow rule, a thermoplastic constitutive equation for orthogonal cutting is derived, in order to investigate the effect of tool rake angle on cutting force, chip contour, equivalent stress distribution, residual stress and the machined workpiece surface. To validate the accuracy of the present cutting model, the simulated cutting force was also compared with experimental values obtained under the same cutting conditions. The comparison indicates that the error between the simulated cutting force and experimental values falls within acceptable limits. The cutting force decreases as the tool rake angle increases. In this paper, the extent of cutting-force reduction is most evident as the rake angle increases from 10 to $15^{\circ}$. In contrast, when the rake angle increases from 15 to $20^{\circ}$, the cutting force experiences only a slight reduction. The maximum equivalent strain on the section decreases as the tool rake angle increases [67]. Multiple criteria including the cutting force, the thrust force, the chip thickness, and the tool-chip natural contact length, $(\mathrm{Fc}, \mathrm{Ft}$, hch, and $\ln$ ) have been employed to compare the experimental and theoretical predictions from both the analytical and FE models, The analytical results show that tool-chip friction along the tool rake face and on the round tool edge decreases with increasing cutting speed and feed rate. The error of prediction from the analytical and FE models is typically less than $12 \%$. The maximum temperature occurs on the round tool edge in small-feed-rate finish machining. This is quite different from the conventional machining, where the maximum temperature occurs not at the tool tip but on the tool rake face at a certain distance from the tool tip. The maximum temperature occurs on the round tool edge under the cutting conditions investigated in this study [2]. Several parameters have been identified as being significant in contributing to residual stress formation. Among the parameters that have been shown to have the most 
influence are tool geometry (cutting edge radius, nose radius, rake angle, flank wear), cutting conditions (cutting speed, feed, depth of cut), and material behavior (hardness, flow-stress). During the residual stress modeling two sources of mechanical stress due to cutting are considered. One is due to contact between the tool edge and the workpiece, and the other is from the stresses in the shear zone. The depth of the maximum compressive residual stress is strongly influenced by the friction coefficient and edge radius. The mechanical load due to the edge radius contributes to compressive residual stress formation. In contrast to the edge radius, larger values for friction impart more tensile character in the residual stress profile. This is due to the decrease in the shear angle caused by higher friction, larger shear loads, and higher temperatures in the workpiece. These factors play a role in the more tensile residual stresses predicted from the model [68].

Author studied the performance of commercial chip breakers using a neural network that was trained through a back propagation algorithm. Important form elements (depth of cut, land, breadth, and radius) that directly influenced the chip formation were chosen among commercial chip breakers, and were used as input values of the neural network. As a result, the performance evaluation method has been developed and applied to commercial tools, which resulted in excellent performance. Further author suggested that if the training data in the neural network is collected with greater consideration given to the effect of cutting conditions and the performance of chip breakers, it can be used for the design of chip breakers in the future [47]. On the basis of Lee and Shaffer's model, author presents an analytical slip-line approach to investigate how the negative tool rake angle and the cutting speed affect the tool-chip friction, and how the tool-chip friction further affects machining performances, such as the ratio of the cutting force to the thrust force, the chip thickness ratio, the geometry of the shear zone, and the geometry of the stagnation zone of material flow adjacent to the tool rake face. Result revels that the negative tool rake angle affects the force ratio $F \mathrm{c} / F \mathrm{t}$, the chip thickness ratio $t 2 / t 1$, and the tool-chip friction factor $\tau / k$ in a manner contrary to a positive tool rake angle does. This has been confirmed by both the predicted and experimental results. The tool-chip friction $\tau / k$ decreases with increasing absolute value of negative tool rake angle $\gamma 1$ and with increasing cutting speed $V \mathrm{c}$ [69]. Author studied the effect of a large radius via FE modeling. The FEM results indicate that a large edge radius is associated with a deep temperature and stress field beneath the machined surface compared with small edge radius [70].

The model developed by Waldorf is used to predict the plowing forces due to tool edge roundness. Waldorf used a slip-line model developed for predicting plowing forces in orthogonal cutting. The model incorporated a small, stable builtup edge of material adhered to the cutting tool. A brief description of the model is provided below. In Figure $10 \mathrm{re}$ is the edge radius $\alpha$ is the rake angle, $f$ is the shear angle, and $t$ is the uncut chip thickness. The fan field angles $q, g$ and $h$ are found from geometric and friction relationships. Details for computing the values are available in. $R$ is the radius of the circular fan field centered at $A$. If the flow stress $k$ of the material is known along with the shear angle $f$, the plowing forces can determined from
Equation (3). Pcut is the plowing force in the cutting direction, Pthrust is the plowing force normal to the newly generated surface, and $w$ is the width of cut.

$$
\begin{gathered}
P_{\text {cut }}=k \cdot w\left[\begin{array}{l}
\cos (2 \eta) \cos (\varphi-\gamma+\eta)+ \\
(1+2 \theta+2 \gamma+\sin (2 \eta)) \sin (\varphi-\gamma+\eta)
\end{array}\right] C A \\
P_{\text {thrust }}=k \cdot w\left[\begin{array}{l}
(1+2 \theta+2 \gamma+\sin (2 \eta)) \cos (\varphi-\gamma+\eta)- \\
\cos (2 \eta) \sin (\varphi-\gamma+\eta)
\end{array}\right] C A
\end{gathered}
$$

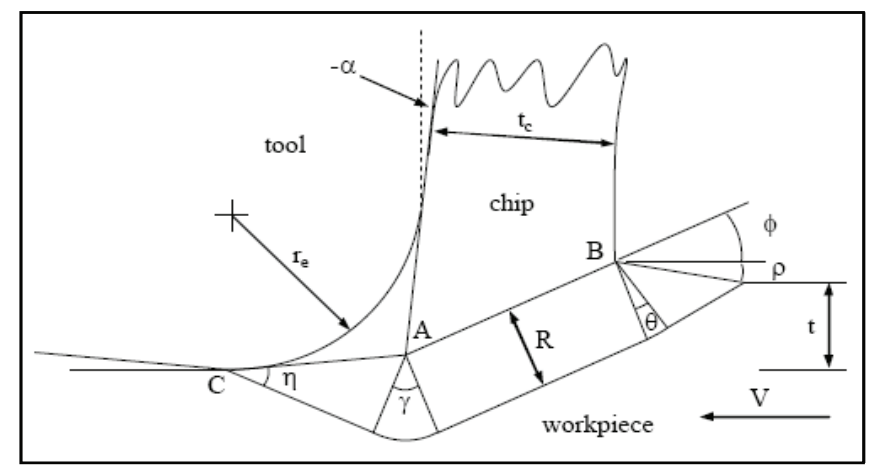

Figure 10. Schematic sketch for turning indicating various angles

FEM simulation of hard turning of AISI 52100 bearing steel is performed that incorporates hardness-based flow stress model and hydrostatic stress-based fracture criterion to simulate the given hard turning process. The nose radius CBN cutting tools in hard machining impose ploughing or burnishing action on the cut surface, resulting in the generation of high hydrostatic stresses in the cutting zones, the latter effecting chip segmentation and fracture. Thus the effects of hardness and hydrostatic stresses are taken into account in the flow stress formulation. Based on the numerical experiment results, the effects of workpiece hardness, cutting edge geometry and process parameters on the residual stress profile in the hard machined surface are investigated. Numerical experiments using FEM models are then utilized to develop an understanding of the subsurface residual stress profiles generated during hard turning. Large hone radius tool produces more compressive residual stress and deeper beneficial length than small hone radius tool. Chamfer tool helps to increase compressive residual stress but its effect is less than that of increasing the hone radius. Therefore, it is recommended that chamfer plus hone radius be used to obtain best residual stress profile [71]. Author has conducted finite element analysis in orthogonal turning of steels with various cutting edge radii. It has been shown that an optimum cutting edge radius exists so as to minimize the Von Mises stresses around the cutting edge, and especially in the coating layer. Moreover milling tests have confirmed that the optimum cutting edge radius found experimentally is of the same order of magnitude as in the case of FEA analysis. It seems to confirm that the minimization of the Von Mises Stresses inside the coating is a good way to maximize the wear resistance of a cutting tool [72]. 


\section{Conclusions:}

1. Large edge hone tools produce statistically higher forces in the axial (feed) and radial (thrust) directions than small edge hone tools. Further large edge hone tools produce higher surface roughness values than small edge hone tools. However, feed dominates surface roughness. The chamfer angle has a great influence on the cutting force and tool stress. All cutting force components increase with an increase in the chamfer angle, especially the level of passive force. Further an increase of chamfer angle will increase tool life up to certain value, after that the tool life decreases. This increase of tool life is due to the increase in wedge strength of the PCBN tool. Also higher value of chamfer angle produces low surface roughness at higher cutting speed.

2. Curvilinear edges (chamfer+ honed) are to protect the cutting edge from chipping, to improve its impact resistance, and to increase surface area for heat transfer from the cutting zone. Curvilinear edge preparation affects chip formation mechanism due to increased cyclical plastic deformations along the face of these edges. Further the magnitude of all the cutting forces is lower at higher cutting speed than at lower speed, it means the honed and chamfered cutting edge geometry influences the cutting forces only when the MRR is low.

3. Chamfer tool helps to increase compressive residual stress but its effect is less than that of increasing the hone radius. Therefore, it is recommended that chamfer plus hone radius be used to obtain best residual stress profile for turning thorough hardened AISI- 52100 bearing grade steel. If required residual stress profile can be assured, use of medium hone radius plus chamfer in cutting edge preparation is a good option to keep tool temperature and cutting force low. As the effect of chamfer is equivalent to the increasing hone radius, medium hone radius $(0.02-0.05 \mathrm{~mm})$ plus chamfer angle of $20^{\circ}$ is recommended.

4. During finish hard turning increase in the rake angle or the chamfer angle as well as the hone cutting edge radius allowed an increase in the compressive residual stress in the subsurface. Further the increased radius of a cutting tool will produce larger compressive residual stress beneath the machined surface. Further large edge hone tools promote continuous white layer formation at feeds above $0.05 \mathrm{~mm} / \mathrm{rev}(0.002 \mathrm{in} / \mathrm{rev})$. While small edge hone tools cause over-tempered regions at feeds above $0.05 \mathrm{~mm} / \mathrm{rev}(0.002 \mathrm{in} / \mathrm{rev})$.

5 . Variable edge preparation inserts perform better than uniform edge preparation, Tool wear is decreased with the use of a variable micro-geometry inserts. As this variable micro-geometry tool design reduces the heat generation along the tool cutting edge. Further this edge induces less plastic strain on the machined workpiece in comparison to uniform edge.

6. Size of tool edge radius is an important factor and it affects the mechanics of cutting. Edge radius must be selected according to cutting conditions. Large edge radius is not suitable for machining low uncut chip thickness. The ratio of uncut chip thickness to edge radius, which is app. equal to three, seems to be an appropriate ratio for edge preparations used in the cutting tests. In finish hard turning white layer depth decreases with increasing nose radius. Further large tool nose radii seem to only have the advantage of finer surface finish, yet tool wear is comparable and specific cutting energy is slightly higher.

7. The nose radius of tool affects the roughness of machined surface, residual stresses of machined surfaces, chip morphology and forces arise during cutting. Further the ratio of the thrust force to cutting force and the ratio of the thrust force to feed force increase with the increase of the tool nose radius. Large tool nose radii seem to have only the advantage of finer surface finish. In comparison to small tool nose radii the large tool nose radii cause almost equal tool wear and a slightly higher specific cutting energy. Large nose radius tools generate shallower white layers in new tool cutting; however, leave deeper white layers when cutting by worn tools. Thus for deciding the life of tool with large nose radius white layer parameter should also be considered a part from flank wear.

8. The optimum performance of RCT mainly depends upon selection of chip breaker groove geometry and combination of different cutting parameters. Using a restricted contact length in the low range of the feed produces a natural contact length which is smaller than the restricted contact length and the chip does not reach the chip-breaker groove. This means that the function of the chip-breaker groove is suspended and the tool with the groove behaves like a tool with a natural contact length. Also using a restricted contact length in the high range of the feed produces a natural contact length, which is several times larger than the restricted contact length. In this case the chip breaks into a short segment of dark blue color along with vibration and high cutting forces. Thus the use of restricted contact length in the correct range of cutting data leads to a controlled chip form and a favorable process in the sense of low cutting forces, low tool temperature and long tool life. Further the beneficial effect of controlled contact cutting with respect to energy reduction becomes more pronounced with an increase in feed rate and depth of cut.

9. The failure of grooved tools is mainly due to improper groove utilization by the chip and this has been resulting from either poor chip-groove design or inappropriate application of the cutting conditions for a particular chip-groove. Further it is suggested that secondary edge form of wear can be averted, by causing the chip-flow angle to be larger (e.g. by reducing depth of cut, etc.), so that the chip strikes the backwall instead of the minor edge.

10. The use of restricted contact length in a high range of cutting data leads to the cutting edge being exposed to a high concentration of a specific compressive stress and temperature, which in turn leads to shorter tool life caused by the rapid plastic deformation of the cutting edge. Also the groove on the rake face helps in smooth flow of the cooling fluid in chip tool interface.

11. The tool-chip friction $\tau / \mathrm{k}$ decreases with increasing absolute value of negative tool rake angle and with increasing cutting speed. A greater negative rake angle gives higher compressive stresses as well as a deeper affected zone below the machined surface.

12. The cutting forces developed in hard metal turning with CVD diamond tools increase with the bluntness of the cutting edge in the following order: sharp $<$ chamfer $<$ hone.

13. Most of the discrepancy between the theoretical surface 
roughness and measured surface roughness in micro turning is due to the additional surface roughening caused by plastic side flow. The big roughness values at low speeds can be attributed to increased side flow caused by the strain-gradient induced strengthening of the material directly ahead of the tool.

14. Increasing the nose radius has a direct effect on cutting forces, leading to a significant increase in the ploughing effect in the cutting zone.

15. The tool chip breaker geometry causes influence on specific cutting energy behavior. Even small modifications on cutting edge geometry affect the cutting force levels and specific cutting energy values.

\section{Recommendations for future work in light of tool geometry aspects:}

1. In the use of variable micro-geometry design if the focus is given to ratio of uncut chip thickness to edge radius process performance can be enhanced. As with decreasing uncut chip thickness to edge radius ratio friction factor increases. Further the effect of variable micro-geometry design should be explored with respect to surface integrity i.e. its impact on residual stresses, white layer formation and micro-hardness variation beneath the machined surface.

2. The use of grooved tools with $\mathrm{CBN}$ materials should be explored in finish turning of hard materials. These tools are recently reported in literature. Also the use of wiper geometry carbide tools with CBN-TiN nano coatings should be explored in hard turning in comparison to costly $\mathrm{CBN}$ tools. Further to include these geometrical parameters effect in the development of models for turning.

3. Edge preparation affects chip formation mechanism further, which can vary the performance parameters in turning opera- tion. So attention should be paid to chamfer angle and chamfer width design for turning process improvement.

4. During hard turning with large nose radius and large negative chamfer angle at small feed rate and depth of cut, the ploughing effect is significant out of the total cutting forces. The prediction accuracy in hard turning could be improved if the force components due to ploughing should be carefully addressed.

5. Research should be focused on to develop chip-breaking predictive models using soft computing, mathematical and FEA techniques for CBN, Ceramics and PCD tools using in machining of difficult to cut materials. Further a detailed comparison of models developed through soft computing and FEM approaches is required in order to identify the clear-cut dependability of these models for industrial use.

6. One should study the effect of tool geometry on serrated chip formation and serration frequency and further the relation of serrated chip formation and frequency of serration on surface integrity of the machined surface.

7. Chamfer tool helps to increase compressive residual stress but its effect is less than that of increasing the hone radius. Therefore, it is recommended that chamfer plus hone radius be used to obtain best residual stress profile for turning.

8. In finish hard turning the optimal selection of nose radius derives from a compromise between residual stresses and surface roughness, as a large nose radius enhances the surface finish but increases residual stresses, and vice versa.

9. To establish a relationship between cutting conditions, tool coatings and chip-groove configurations on tool-wear and toollife. It means focus should be there to develop a new tool-life relationships for turning operations by considering the groove geometry and coating type apart from considering cutting conditions, work and tool material properties.

\section{References}

1. Thiele, J. D., Melkote, S. N., Peascoe, Ra., Watkins, T. R. (2000) "Effect of cutting edge geometry and workpiece hardness on surface residual stress in finish hard turning of AISI52100 steel", Transactions of the ASME, Vol. 122, pp.642-649.

2. Fang, N., and Fang, G. (2007) "Theoretical and experimental investigations of finish machining with a rounded edge tool", Journal of Materials Processing Technology, Vol.191, pp.331-334.

3. Thiele, J. D., and Melkote, S. N. (1999) "Effect of Cutting Edge Geometry and Workpiece Hardness on Surface Generation in the Finish Hard Turning of AISI 52100 Steel", Journal of Materials Processing Technology, Vol. 94, pp.216-226.

4. Joel, RECH. (2005) "Cutting edge preparation and surface issues", HSS forum International conference "smart solutions for metal cutting", Aachen, 2-3 Feburary, pp.1-12.

5. Poulachon, G., Moison, A., and Jawahir I.S. (2001) "On Modeling the influence of thermo-mechanical behavior in Chip Formation During Hard Turning of 100Cr6 Bearing Steel", Annals of the CIRP, Vol. 50, No.1, pp.31-36.

6. Tae-Hong Lee, (2007) "An experimental and theoretical investigation for the machining of hardened alloy steel", PhD Thesis, University of South Vales Australia.

7. Altin, A., Gokkaya, H., and Nalbant, M., (2007) "The effect of cutting speed and cutting tool geometry on machinability properties of nickelbase Inconel 718 superalloys", Materials and Design, Vol. 28, No.4, pp.1334-1338.

8. Hughes J. I., Sharman A. R., and Ridgwayk, C. (2006) "The effect of cutting tool material and edge geometry on tool life and workpiece surface integrity", Proceedings of the Institution of Mechanical Engineers. Part B. Journal of Engineering Manufacture, Vol. 220, No.2, pp.93-107.

9. Zhou, Li., (2001) "Machining Chip-Breaking Prediction with Grooved Inserts in Steel Turning", Ph.D Thesis.

10. Karpat Yigit., and Ozel, Tugrul. (2008) "Mechanics of high speed cutting with curvilinear edge tools", International Journal of Machine Tools \& Manufacture, Vol. 48, pp.195-208.

11. Paulo, Davim J., Figueira, L., 2007. Comparative evaluation of conventional and wiper ceramic tools on cutting forces, surface roughness, and tool wear in hard turning AISI D2 steel. Proceedings of the Institution of Mechanical Engineers. Part B. Journal of Engineering Manufacture. 221(4):625-633.

12. Grzesik, W., Wanat, T. 2006. Surface finish generated in hard turning of quenched alloy steel parts using conventional and wiper ceramic inserts. International Journal of Machine Tools and Manufacture.46(15): 19881995.

13. Hirao, M., Tlusty, J., Sowerby, R., Chandra, G., 1982. Chip formation with chamfered tools. Journal of Engineering for Industry. Trans. of ASME. 104:339-342.

14. Thiele, JD., Melkote, S.N., 1999. The effect of tool edge geometry on workpiece sub-surface deformation and through thickness residual stress 
for hard turning of AISI52100 steel. Trans. NAMRI/SME.27:135-140.

15. Jeffrey, D., Shreyes, N.M., 1999. Effect of cutting edge geometry and workpiece hardness on surface residual stresses in finish hard turning of AISI52100 steel. Manufacturing Science and Engineering ASME. MED10:805-979.

16. Lahiffa, Cora., Gordonb, Seamus., Phelan, Pat., 2007. PCBN tool wear modes and mechanisms in finish hard turning. Robotics and ComputerIntegrated Manufacturing.23: 638-644.

17. Matsumoto, Y., Hashimoto, F., Lahoti, G., 1999. Surface integrity generated by precision hard turning. Annals of the CIRP.48: 59-62.

18. Kurt, Abdullah., Seker, Ulvi., 2005. The effect of chamfer angle of polycrystalline cubic boron nitride cutting tool on the cutting forces and the tool stresses in finishing hard turning of AISI 52100 steel. Materials and Design.26: 351-356.

19. Dawson, G., 2002. Machining hardened steel with polycrystalline cubic boron nitride cutting tools. Ph.D. Thesis, Georgia Institute of Technology.

20. Zhou, J. M., Walter, H., Andersson, M., and Stahl, J. E. (2003) "Effect of chamfer angle on wear of PCBN cutting tool", International Journal of Machine Tools \& Manufacture, Vol. 43, pp.301-305.

21. Pawade, R. S., Joshi, Suhas S., Brahmankar, P. K., and Rahman, M. (2007) "An investigation of cutting forces and surface damage in high-speed turning of Inconel-718", Journal of Materials Processing Technology, Vol. 192-193, pp.139-146.

22. Nalbant, Muammer., Altın, Abdullah., and Gokkaya, Hasan. (2007) "The effect of cutting speed and cutting tool geometry on machinability properties of nickel-base Inconel-718 super alloys", Materials and Design, Vol. 28, pp.1334-1338.

23. Coelho, R.T., Silva, L. R., Braghini, A. Jr., and Bezerra, A. A. (2004) "Some effects of cutting edge preparation and geometric modifications when turning INCONEL-718TM at high cutting speeds", Journal of Materials Processing Technology, Vol. 148, pp.147-153.

24. Hua, Jiang., Shivpuri, Rajiv., Cheng, Xiaomin., Vikram, Bedekar., Matsumoto, Yoichi., Fukuo, Hashimoto., and Watkins, Thomas R. (2005) "Effect of feed rate, workpiece hardness and cutting edge on subsurface residual stress in the hard turning of bearing steel using chamfer+honed cutting edge geometry", Materials Science and Engineering, Vol. A 394, pp.238-248.

25. Hua, Jiang., Umbrello, Domenico., and Shivpuri, Rajiv. (2006) “Investigation of cutting conditions and cutting edge preparations for enhanced compressive subsurface residual stress in the hard turning of bearing steel", Journal of Materials Processing Technology, Vol. 171, pp.180-187.

26. Almeida,F.A., Oliveira, F.J., Sousa ,M., Fernandes, A.J.S., Sacramento, J., and Silva, R.F. (2005) "Machining hard metal with CVD diamond direct coated ceramic tools: effect of tool edge geometry", Diamond \& Related Materials, Vol. 14, pp.651-656.

27. Ren, H., and Altintas, Y. (2000) "Mechanics of machining with chamfered tools", ASME Journal of Manufacturing Science and Engineering, Vol. 122, pp.650-659.

28. Manjunathaiah, J., and Endres, W. J. (2000) "A new model and analysis of orthogonal machining with an edge-radiused tool", ASME Journal of Manufacturing Science and Engineering, Vol. 122, pp.384-390.

29. Tugrul, Ozel., Tsu-Kong, Hsu., and Erol, Zeren. (2005) "Effects of cutting edge geometry, workpiece hardness, feed rate and cutting speed on surface roughness and forces in finish turning of hardened AISI H13 steel", International Journal of Advance Manufacturing Technology, Vol. 25, pp.262269.

30. Noordin, M. Y., Kurniawan, D., and Sharif, S. (2007) "Hard turning of stainless steel using wiper coated carbide tool", International Journal of Precision Technology, Vol. 1, No.1, pp.75-84.

31. Karpat, Y., and Ozel, T. (2008) "Process simulations for 3D turning using uniform and variable micro-geometry PCBN tools", International Journal of Machining and Machinability of Materials, Vol. 3, No.3, pp.250-262.

32. Shaffer, W. (2000) 'Getting A Better Edge', Cutting Tool Engineering, Vol.52, No.3, pp.44-48.

33. Klocke, F., and Kratz, H. (2005) "Advanced Tool Edge Geometry for High Precision Hard Turning", Annals of the CIRP, Vol. 54, No.1, pp.47-50.

34. Ozel, T., Karpat, Y., and Srivastava, A. (2008) "Hard turning with variable micro-geometry PCBN tools", CIRP Annals - Manufacturing Technology, Vol.57,pp.73-76. doi:10.1016/j.cirp.2008.03.063
35. Beauchamp, Y., Thomas, M., Youssef, A., and Jacques, Masounave. (1996) "Investigation of cutting parameter effects on surface roughness in lathe boring operation by use of a full factorial design." Computers and Industrial Engineering, Vol. 31, No.3-4, pp.645-651.

36. Kishawy, H. A., and Elbestawi, M. A. (1997) "Effect of process parameters on chip morphology when machining hardened steel", Manufacturing Science and Engineering ASME, Vol.6-2, pp.13-20.

37. Ravindra, Thamma., Comparison Between Multiple Regression Models to Study Effect of Turning Parameters on the Surface Roughness, Proceedings of The (2008) IAJC-IJME International Conference

38. Schimmel, Roy J., Manjunathaiah, Jairam., and Endres, William J.(2000) "Edge Radius Variability and Force Measurement Considerations", Journal of Manufacturing Science and Engineering, Vol. 122, pp.590-593.

39. Fang, N. (2003) "Slip-line modeling of machining with a rounded-edge tool - part I: new model and theory", Journal of the mechanics and physics of solids, Vol. 51, pp.715-742.

40. Meng Liu., Jun-ichiro, Takagi., and Akira, Tsukuda. (2004) "Effect of tool nose radius and tool wear on residual stress distribution in hard turning of bearing steel", Journal of Materials Processing Technology, Vol. 150, pp.234-241.

41. Chou, Y. K., and Song, Hui. (2004) "Tool nose radius effects on finish hard turning', Journal of Materials Processing Technology, Vol. 148, pp. 259-268.

42. Sasahara, H. Obikawa, T. Shirakashi, T. (2004) 'Prediction model of surface residual stress within a machined surface by combining two orthogonal plane models', International Journal of Machine Tools \& Manufacture, Vol.44, pp.815-822.

43. Jeffrey,D.T. and shreyes, N.M. The effect of tool edge geometry on workpiece subsurface deformation and through-thickness residual stress for hard turning of AISI 52100 steel. Trans. Of NAMRI/SME, XXVII, 1999,135-140.

44. Liu,Meng., Takagi, Jun-ichiro., and Tsukuda, Akira. Effect of tool nose radius and tool wear on residual stress distribution in hard turning of bearing steel. Journal of Materials Processing Technology, 2004,150, 234-241.

45. Jawahir, I. S. (1998) "A survey and future predictions for the use of chip breaking in unmanned systems", The international Journal of Advanced Manufacturing Technology, Vol. 3, No.4, pp.87-104.

46. Juneja, B. L., Sekhon, G. S. (1987) "Fundamentals of metal cutting and machine tools", Wiley Eastern, New Delhi, India.

47. Hong-Gyoo Kim, Jae-Hyung Sim, Hyeog-Jun Kweon,(2009) "Performance evaluation of chip breaker utilizing neural network", Journal of Materials Processing Technology, Vol. 209, No.2, pp.647-656. doi:10.1016/j. jmatprotec.2008.02.064

48. Nakayama, K. (1962) "A study on chip breaker", Bull. JSME, Vol. 5, No.17, pp.142-150

49. Jawahir, I. S. (1988) 'The Tool Restricted Contact Effect as a Major Influencing Factor in Chip Breaking: an Experimental Analysis', CIRP Annals, Vol.37, pp.121-126. doi:10.1016/S0007-8506(07)61600-X

50. Chao, B. T. and Trigger, K. J. (1959) "Controlled Contact Cutting Tools", ASME Journal of Engineering for Industry, Vol. 81, pp.139-151.

51. Fang, N., and Jawahir, I. S. (2003) "Analytical Prediction of the Chip Back-Flow Angle in Machining With Restricted Contact Grooved Tools", Journal of Manufacturing Science and Engineering, Vol. 125, pp.210219.

52. Jawahir, I. S., Ghosh, R., Fang, X. D., and Li, P. X. (1995) “An investigation of the effects of chip-flow on tool-wear in machining with complex grooved tools", Vol. 184, pp.145-54.

53. Grezsik W., and Kwiatkowska, E. (1997) "An energy approach to chipbreaking when machining with grooved tool inserts", International Journal of Machine Tools \& Manufacture, Vol. 37, No.5, pp. 569-577.

54. Jawahir, I.S. (1990) 'On the controllability of chip breaking cycles and modes in metal cutting', Annals of the CIRP, Vol. 39, No.1, pp.47-51.

55. Wanigarathne, P. C. Kardekar, Dillon, A. D. Poulachon. O. W. G., and Jawahir, I. S. (2005) "Progressive tool-wear in machining with coated grooved tools and its correlation with cutting temperature", Wear, Vol. 259, pp.1215-1224.

56. Sadik, M. 1. and Lindstrom, B. O. (1995) "The Effect of Restricted Contact Length on Tool Performance", Journal of Materials Processing Technology, Vol. 48, pp.275-282.

57. Deshayes, L. (2007) "Analysis of an equivalent tool face for the cutting 
speed range prediction of complex grooved tools", Journal of Materials Processing Technology, Vol. 190, pp.251-262.

58. Dhar, N. R. Paul, S., and Chattopadhyay, A. B. (2001) "The influence of cryogenic cooling on tool wear, dimensional accuracy and surface finish in turning AISI 1040 and E4340C steels", Wear, Vol. 249, pp.932-942.

59. Trent, E. M. and Wright, P. K. Metal Cutting, 4th Edn, 2000, Butterworth Heinemann, Oxford.

60. Shih, A. J. (1996) "Finite element analysis of the rake angle effects in orthogonal metal cutting”, International Journal of Mechanical Science, Vol. 38, No.1, pp.1-17.

61. Jacobson, M., (2002) "Surface Integrity of Hard-Turned M50 Steel”, Proceedings of the Institution of Mechanical Engineers, Part B: Journal of Engineering Manufacture, Vol. 216, No.1, pp 47-54.

62. Patrik, Dahlman. Fredrik, Gunnberg. and Michael, Jacobson. (2004) "The influence of rake angle, cutting feed and cutting depth on residual stresses in hard turning", Journal of Materials Processing Technology, Vol. 147, pp.181-184.

63. Baldoukas, A. K., Soukatzidis, F. A., Demosthenous, G. A., Lontos, A. E., (2008) "Experimental investigation of the effect of cutting depth", tool rake angle and workpiece material type on the main cutting force during a turning process, 3rd International Conference on Manufacturing Engineering (ICMEN), Chalkidiki, 1-3 October, Greece, pp.47-55.

64. Arunachalam, R. M. Mannan, M. A., and Spowage, A. C. (2004) "Surface integrity when machining age hardened Inconel 718 with coated carbide cutting tools", International Journal of Machine Tools \& Manufacture, Vol. 44, pp.1481-1491.

65. Philippe Boisse., Taylan Altan., and Kees Van Luttervelt. (2007) "Fric- tion \& Flow Stress in Forming \& Cutting”, viva books Pvt Ltd.N. Delhi, India.

66. Mustafa Gunay, Ersan Aslan, Ihsan Korkut, and Ulvi Seker.(2004) "Investigation of the effect of rake angle on main cutting force", International Journal of Machine Tools \& Manufacture, Vol. 44, pp. 953-959. doi:10.1016/j.ijmachtools.2004.01.015

67. Ship-Peng, Lo. (2000) "An analysis of cutting under different rake angles using the finite element method", Journal of Materials Processing Technology, Vol. 105, pp.143-151.

68. Jiann-Cherng, Su. (2006) "Residual Stress Modeling in Machining Processes", Ph.D dissertation, Georgia Institute of Technology.

69. Fang, N. (2005) "Tool-chip friction in machining with a large negative rake angle tool", Wear, Vol. 258, pp.890-897.

70. T. Özel and E. Zeren, (2007) "Finite Element Analysis of The Influence of Edge Roundness on The Stress and Temperature Fields Induced by High Speed Machining", International Journal of Advanced Manufacturing Technology, Vol. 35, No.3-4, pp. 255-267.

71. Jiang Hua, Domenico Umbrello, and Rajiv Shivpuri. (2006) "Investigation of cutting conditions and cutting edge preparations for enhanced compressive subsurface residual stress in the hard turning of bearing steel", Journal of Materials Processing Technology, Vol. 171, pp.180-187.

72. J. Rech, Y. C. Yen, H. Hamdi, and T. Altan, (2004) "Influence of cutting edge radius of coated tool on chip formation in orthogonal turning of alloy steel", International conference NUMIFORM, Columbus (USA), 13-17 June. 